\title{
Florida's Introduced Reptiles: Green Iguana (Iguana iguana) ${ }^{1}$
}

\author{
Paige Borcyk, Elizabeth Fortner, Natalie M. Claunch, and Steve A. Johnson ${ }^{2}$
}

\section{Introduction}

Florida has the unfortunate distinction of being the global epicenter for nonnative reptiles, due to the intentional or unintentional actions of people. The state's mild climate, abundant rainfall, expansive areas modified by humans, numerous international ports of entry (sea and air), as well as a thriving exotic pet trade all contribute to reptile invasions. Historically, the introduction of reptiles into Florida was unintentional; reptiles were stowaways in shipments of cargo. The first documented reptile introduction to Florida was that of the brown anole (Anolis sagrei) in the late 1800 s (1). This small lizard likely arrived accidentally in a shipment of cargo originating from Cuba. Since then, more than 150 additional nonnative reptile species have been documented in Florida, the vast majority of which were brought here through the pet reptile trade (2).

Although most introductions do not result in the establishment of breeding populations of nonnative reptiles, many do. Of those species that become established, some thrive and expand, eventually becoming invasive. We define an invasive species of reptile as one that a) is not native to a specific geographic area (in this case the state of Florida), b) was introduced by the intentional or unintentional actions of humans, and c) does or can cause harm to the environment, economy, or human quality of life (3). A well-known example of an invasive reptile in Florida is the Burmese python. This large species of snake was imported for the exotic pet trade, and by way of escapes and/or purposeful releases of pets, became established in the Everglades. Scientific studies have shown invasive pythons have caused severe declines of native mammals in the Everglades (4, 5 ) and have introduced parasites affecting Florida's native snakes $(6,7)$. Further, state and federal agencies have spent millions of dollars to manage impacts of pythons and prevent them from expanding their range farther north in the Peninsula and south into the Florida Keys.

This publication summarizes general knowledge about the green iguana (Iguana iguana) in Florida. It is one in a series of similar publications showcasing a suite of commonly seen or unique introduced reptiles that are established in the state. The biology and impacts of some of these species are well known, whereas others are poorly studied. This fact sheet and others in the series were produced by undergraduate students in the course Invasion Ecology of Amphibians and Reptiles, which was taught in fall semester 2020 at the University of Florida. The target audience for all the documents in the series is homeowners and other residents and visitors who are curious about Florida's diverse wildlife. Our goal is to increase knowledge and raise awareness about the many introduced and invasive reptiles in Florida, as well as to motivate people to take action in the fight to curtail the spread of introduced reptiles in the Sunshine State.

1. This document is WEC440, one of a series of the Department of Wildlife Ecology and Conservation, UF/IFAS Extension. Original publication date July 2021. Visit the EDIS website at https://edis.ifas.ufl.edu for the currently supported version of this publication.

2. Paige Borcyk, previous undergraduate student, Department of Wildlife Ecology and Conservation; Elizabeth Fortner, previous undergraduate student, Department of Wildlife Ecology and Conservation; Natalie M. Claunch, previous graduate student, School of Natural Resources and Environment; and Steve A. Johnson, associate professor and Extension specialist, Department of Wildlife Ecology and Conservation, UF/IFAS Extension, Gainesville, FL 32611.

The Institute of Food and Agricultural Sciences (IFAS) is an Equal Opportunity Institution authorized to provide research, educational information and other services

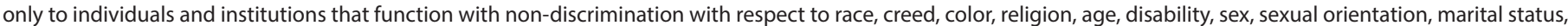

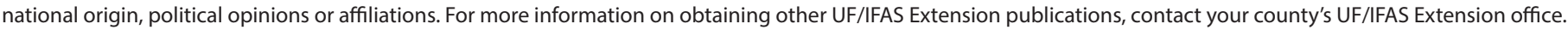
U.S. Department of Agriculture, UF/IFAS Extension Service, University of Florida, IFAS, Florida A \& M University Cooperative Extension Program, and Boards of County Commissioners Cooperating. Nick T. Place, dean for UF/IFAS Extension. 


\section{Identifying Green Iguanas}

As their common name suggests, green iguanas are usually green, and juveniles are particularly bright green (Figure 1). Adults vary from bold to dull green but also may be olive or brown colored (Figures 2-4). Males in breeding condition may even be strikingly orange (Figure 5). Their shade varies with temperature, and they tend to be darker during cool weather to better absorb the warmth from the sun. Regardless of their color, all green iguanas share several distinguishing features. They have long tails but relatively short legs with long toes and sharp claws for climbing. Both sexes have a flap of skin hanging from their lower jaw (called a dewlap) and a large round scale at the rear of the jaw (8), as seen in the adult male in Figure 6. They also have a row of spike-like scales on their neck, back, and a portion of the tail (Figure 4). These scales are typically longer in mature males than in females (8). Green iguanas grow much larger than any native lizards in Florida. Males can grow to over 6 feet long (including the tail), whereas females can reach just over 5 feet, and the tail accounts for as much as three quarters of their total length (8). Hatchling green iguanas measure about 7 inches excluding the tail (9).

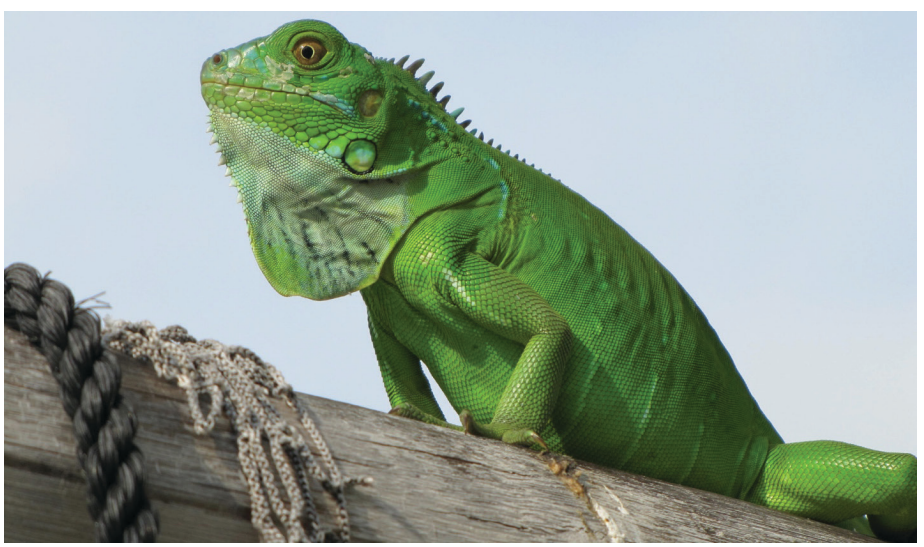

Figure 1. Juvenile green iguanas (Iguana iguana) are a bold green color, such as this individual from Key Largo, Florida.

Credits: Dr. Steve A. Johnson, UF/IFAS

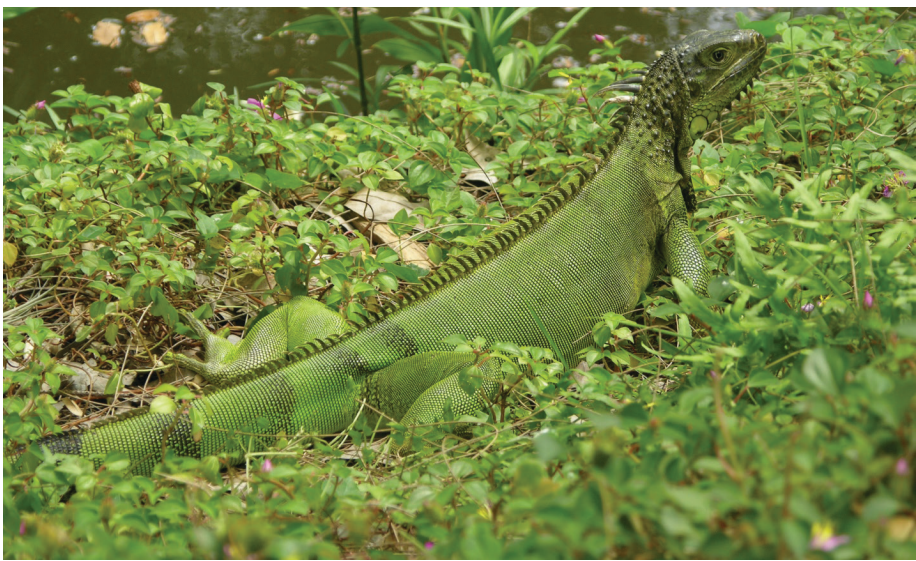

Figure 2. Juvenile and adult green iguanas (Iguana iguana) may be green, but many adults are not green.

Credits: Dr. Steve A. Johnson, UF/IFAS

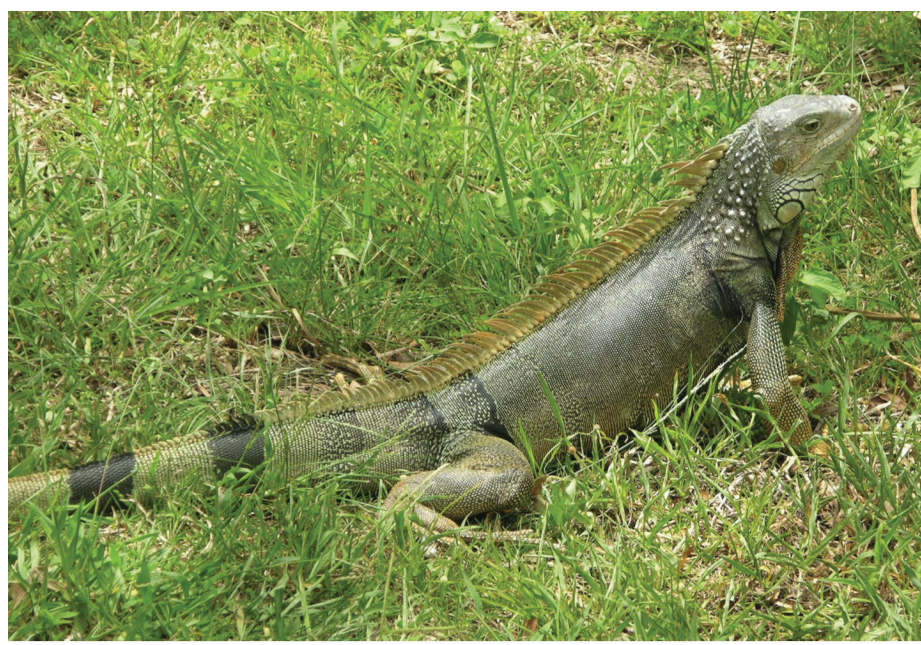

Figure 3. Adult green iguanas (Iguana iguana) may be a dull green or olive color.

Credits: Dr. Steve A. Johnson, UF/IFAS

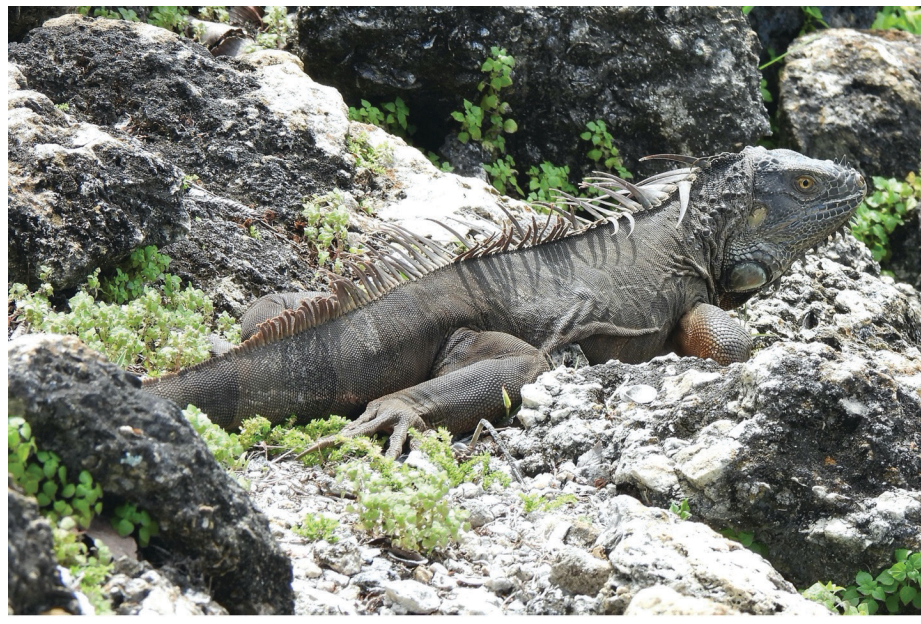

Figure 4. It's not uncommon to see an adult green iguana (Iguana iguana) that is not green, such as this brownish-gray adult. No matter their color, adult green iguanas always have a prominent row of spikelike scales on their back.

Credits: Dr. Steve A. Johnson, UF/IFAS

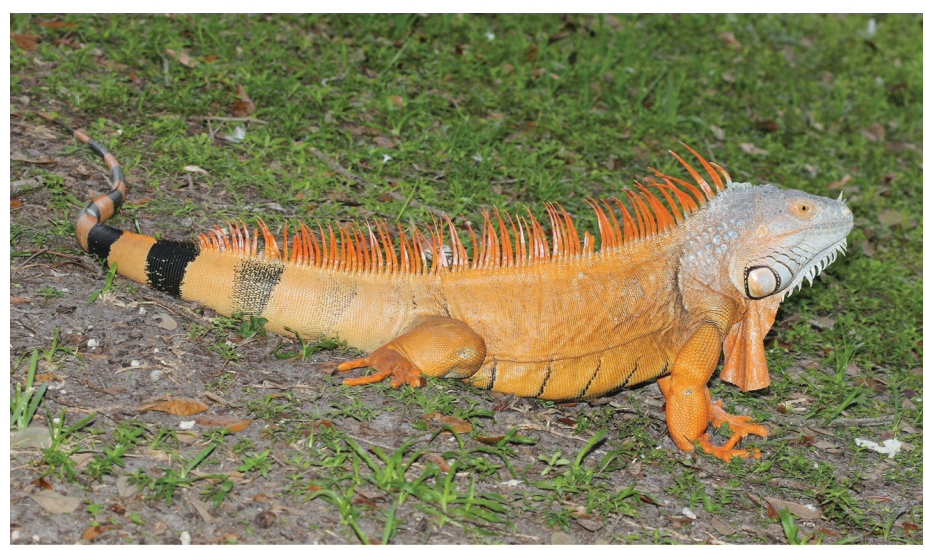

Figure 5. Once they mature and are in breeding condition, male green iguanas (Iguana iguana) can become various shades of orange. Credits: Kevin Enge, Florida Fish and Wildlife Conservation Commission 


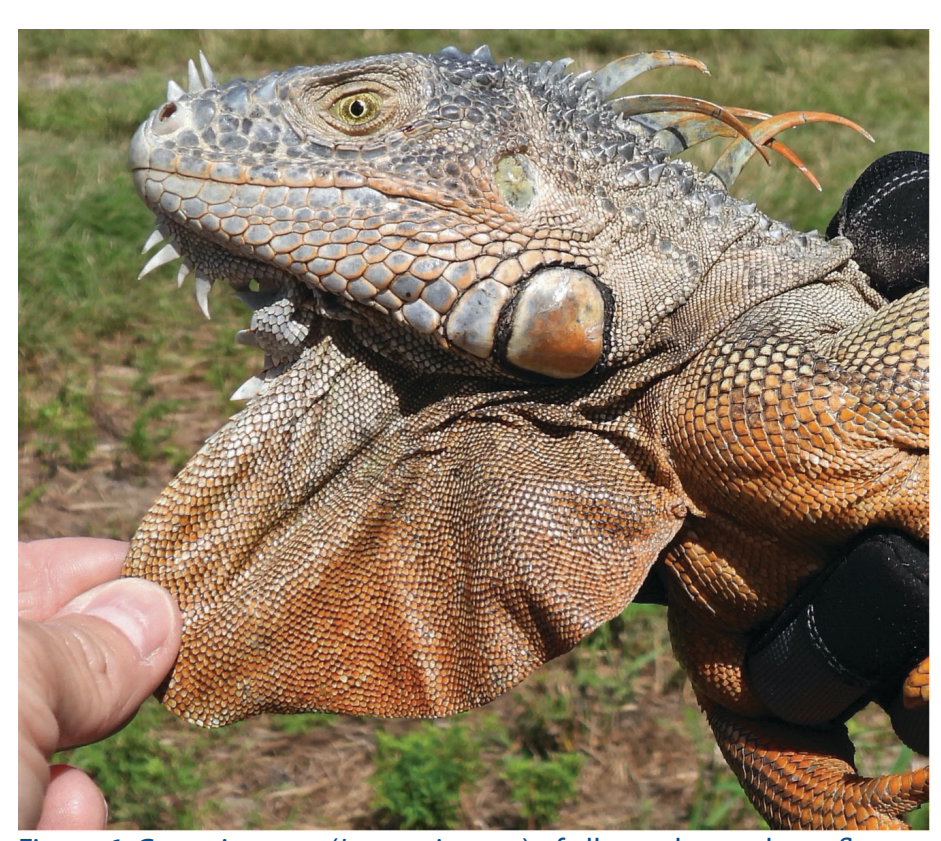

Figure 6. Green iguanas (Iguana iguana) of all ages have a large flap of skin, called a dewlap, hanging from their throat and a large, round scale at the rear of their jaw.

Credits: Dr. Steve A. Johnson, UF/IFAS

\section{Similar-Looking Species}

Although no species of native Florida lizard is likely to be misidentified as a green iguana, there are several introduced species that could be mistaken for a green iguana. The black spiny-tailed iguana (Ctenosaura similis) is established in many of the same areas as the green iguana, namely along the southern Gulf and Atlantic coasts and some of the Florida Keys (8). The two species' body plans are similar, but black spiny-tailed iguanas are shorter than green iguanas (8). The black spiny-tailed iguana has spines along its back like the green iguana, but they are not as long as those of green iguanas of the same size (Figure 7). As their name implies, spiny-tailed iguanas have rings of sharp, pointed scales on their tails (Figure 8 ) that are not present on green iguanas. Adult black spiny-tailed iguanas are normally brown or gray with several dark bands on their back, but young ones are often green and could be mistaken for a small green iguana-look for the rows of spines on the tail. Another introduced species of iguana in Florida is the Mexican spiny-tailed iguana (Ctenosaura pectinata). This species looks almost identical to the black spiny-tailed iguana, and the two can be difficult for scientists to distinguish $(9,10)$.

Juvenile green iguanas may be confused with the introduced knight anole (Anolis equestris), which also occurs in south Florida. Adult knight anoles are about 5-6.5 inches long excluding the tail (11), so roughly the same length as a hatchling green iguana. Both are vibrant green, but the knight anole has yellow (sometimes white) stripes under its eyes and on it shoulders and lacks the round scale at the rear of the jaw (Figure 9). The knight anole's head is more elongated and arrow-shaped than the head of a green iguana, which is more rounded.

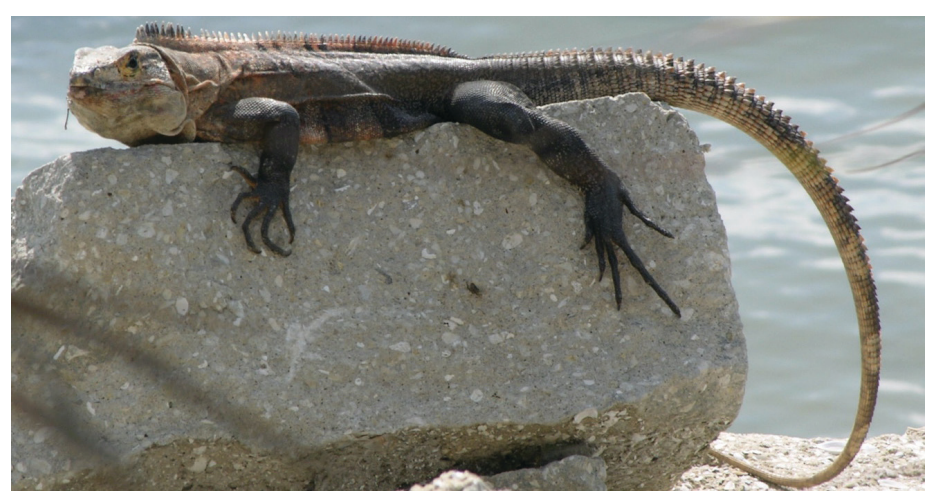

Figure 7. Spiny-tailed iguanas (Ctenosaura similis) look like green iguanas (Iguana iguana), but they don't have an enlarged scale at the rear of their jaw.

Credits: Dr. Steve A. Johnson, UF/IFAS

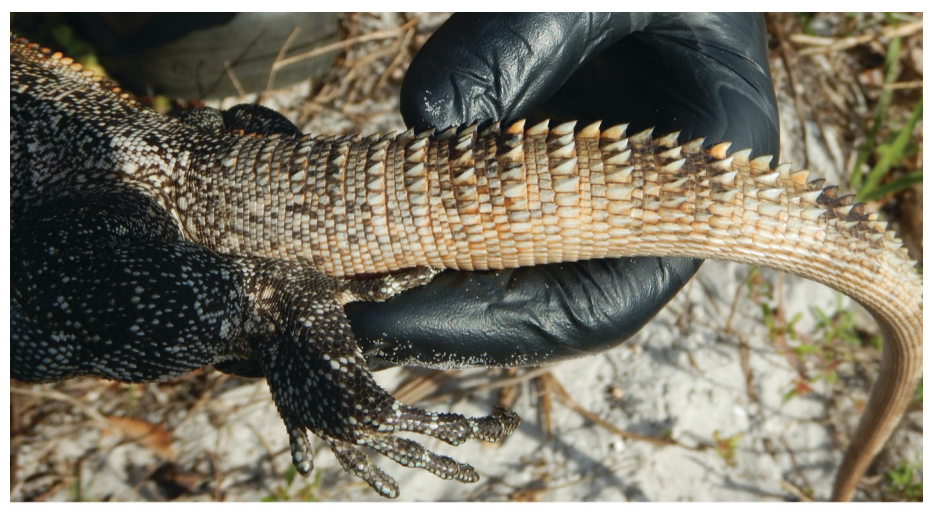

Figure 8. Green iguanas (Iguana iguana) have relatively smooth tails, but as their name indicates, spiny-tailed iguanas have rings of pointed scales on their tails, as shown in this image.

Credits: Dr. Steve A. Johnson, UF/IFAS

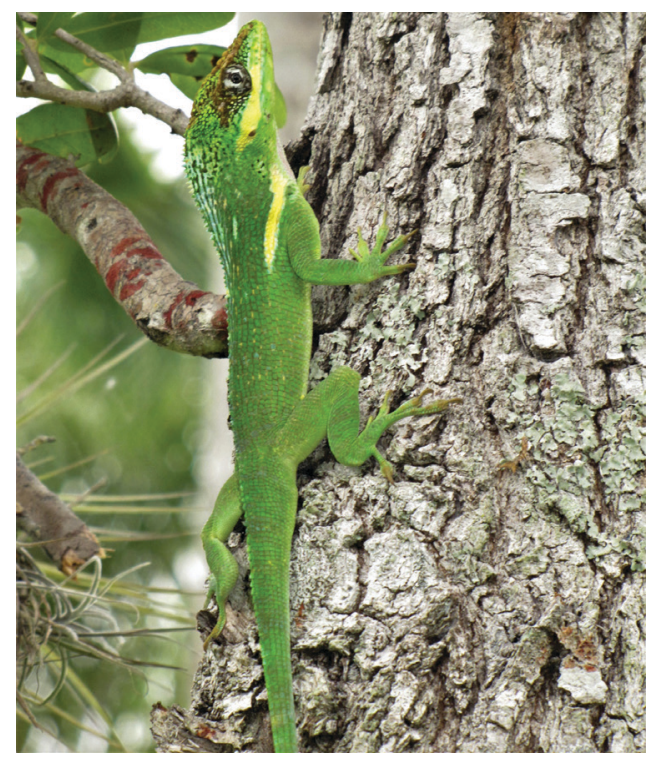

Figure 9. A large knight anole (Anolis equestris) may be misidentified as a very small green iguana (Iguana iguana). But knight anoles have yellow or white stripes under their eyes and on their shoulders. Green iguanas do not have stripes under their eyes or on their shoulders. Credits: Dr. Steve A. Johnson, UF/IFAS 


\section{Native Range}

Green iguanas naturally range from central Mexico south to Paraguay and Brazil in South America. They are also native to some Caribbean islands near the Central and South American coast. They occur in tropical rainforest, dry forest, and savanna habitat, often near water (11).

\section{Mode of Introduction to Florida}

Green iguanas were first documented in Florida in the Miami area in the early 1960s, and an exotic pet dealer is known to have purposely released more than 300 of them in that area in 1964 (13). Since then, additional intentional and unintentional releases of pet iguanas have likely contributed to their spread in peninsular Florida. Green iguanas have been among the most popular pet reptiles in the United States and Florida (10) because they are attractive and relatively easy to care for when small. However, they become more difficult to keep and their cage requirements become more challenging as they grow, making it more likely they will be intentionally released and contribute to the invasive reptile problem in Florida.

\section{Florida Range and Habitats}

Based on museum records and numerous observations reported in EDDMapS (https://www.eddmaps.org/), green iguanas appear to be established in much of central and southern Florida, including the Keys. On the mainland they occur mainly near the coast (Figure 10). The northern extent of their Florida distribution is limited by cold temperatures. In their introduced ranges, green iguanas are common in urbanized landscapes (14). In addition to thriving in human-modified areas in Florida (e.g., suburban neighborhoods), they also inhabit natural habitats such as mangroves and pinelands (8). They are common along canals and levees in southern Florida, and their ability to colonize such areas, which can act as corridors for dispersal, has likely contributed to their range expansion (15).

\section{Ecology}

Green iguanas are excellent climbers and prefer areas with trees, but they also occur in places lacking them. They are almost always found near permanent water and are strong swimmers (10). When startled, they are quick to dive into water (8), only crawling back on land after the perceived threat has passed (Figure 11). They are active during the day and are frequently seen on the ground or in trees and shrubs warming themselves in the sun (basking). In places where they are used to human activity, they will bask on sidewalks, golf courses, sea walls, docks, rocks, parking lots, and lawns. At night they sleep in trees (if present), crevices in rocks, and burrows they dig. They will also shelter in drainage pipes, culverts, piles of debris, and similar hiding places created by people (15). They use their burrows and other underground refugia as hiding places when disturbed by people.

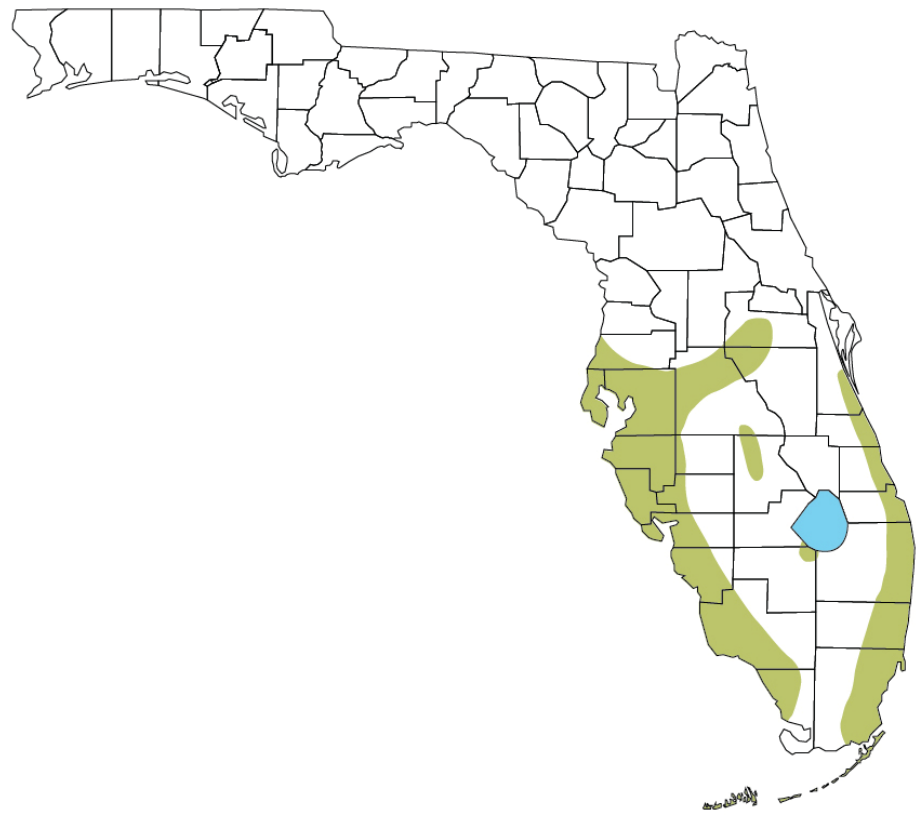

Figure 10. Green iguanas (Iguana iguana) occur throughout much of the southern half of Florida's Peninsula but are most common near the coast (see green shaded areas). Report sightings of green iguanas, especially those seen outside of the shaded areas indicated on this map. Take a digital picture of the lizard and report your observation to EDDMapS.org.

Credits: Tracy Bryant, UF/IFAS

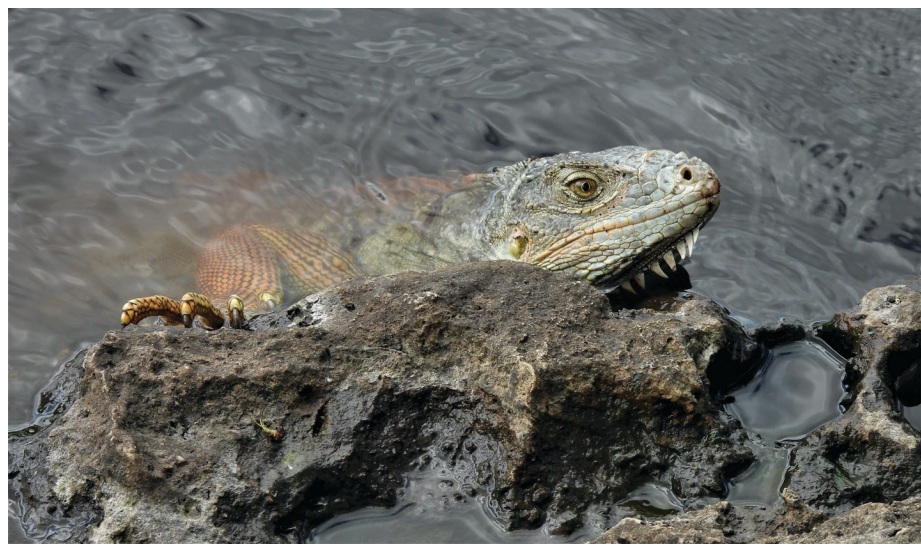

Figure 11. Green iguanas (Iguana iguana) are excellent swimmers and are usually found near water. When they feel threatened, they are quick to dive into water, even from high in a tree, and only crawl back onto land when it is safe to do so.

Credits: Dr. Steve A. Johnson, UF/IFAS

The green iguana is largely herbivorous and eats a variety of plants. They prefer flowers, fruits, tender shoots, and many ornamental plants $(15,16)$ but typically avoid citrus and thick-leaved plants (16). Hatchlings and juveniles eat insects in addition to vegetation (15). Juveniles and adults 
have been documented eating tree snails, and adult green iguanas will occasionally eat small vertebrates and bird eggs and will even scavenge carrion $(8,9,14,15)$.

Like most reptiles, the green iguana lays eggs. Females dig relatively shallow nest burrows that are about 1 foot deep and up to 3 feet long (15). In their native range, females may nest communally and create a series of connected burrows (12). They lay approximately 10 to 70 eggs in these nest burrows, and the eggs incubate for 2-3 months without parental care (8). A study in southern Florida found that males can reach sexual maturity as early as 16 months and females as early as 24 months (9). The breeding season in Florida is between December and April with hatchlings appearing during the summer (15). In the absence of predators or competitors, green iguanas can live a long time, reaching 15-20 years old (17).

Because they grow large, adult iguanas have few predators in Florida, other than humans. Domestic dogs will kill adult iguanas (11), and American alligators and crocodiles are potential predators (15), but only the eggs and very young iguanas are usually at risk of predation. Mammalian predators of green iguana eggs in Florida include gray foxes and likely raccoons $(9,18)$. Raccoons also eat hatchlings and very young iguanas, and raccoon predation may suppress iguana population growth under the right circumstances (9). Additional predators of very small iguanas include several species of birds, as summarized in scientific publications $(15,19)$.

\section{Negative Ecological Effects}

Green iguanas have been documented using the burrows of Florida's native Burrowing Owl and gopher tortoise, both of which are listed as threatened species by the state $(8,17)$. The presence of iguanas could potentially displace these native species from their burrows. Green iguanas will occasionally eat bird eggs $(16,17)$, but to date there is no scientific evidence that they have harmed bird populations in Florida. Green iguanas are primarily herbivorous and eat flowers, leaves, and fruits of ornamental plants. As a result, they could transport seeds of cultivated plants, including invasive species, into nearby natural areas and undermine efforts to control invasive plants in nature preserves (15). However, a study of green iguana movements in southeast Florida found that iguanas at two locations did not move very far, suggesting that their impacts to natural areas through seed dispersal may be minimal (20).

Gray nickerbean (Guilandina bonduc) is among the many plants that green iguanas feed on in south Florida. This species is one of two primary host plants for caterpillars of the Miami blue butterfly (Cyclargus thomasi bethunebakeri), which only occurs in Florida and is a federally listed endangered species (Figure 12). The Miami blue prefers to lay its eggs on developing shoots and flower buds of the nickerbean. This small butterfly has only been found in three places in the past 20 years-Key West National Wildlife Refuge, Great White Heron National Wildlife Refuge, and Bahia Honda State Park (21). In the early 2000s, green iguanas at Bahia Honda State Park were eating so much nickerbean that scientists concluded they were depriving the Miami blue butterflies of their food and may have been one of several potential factors that contributed to the eventual loss of the Miami blue population at Bahia Honda State Park $(21,22)$.

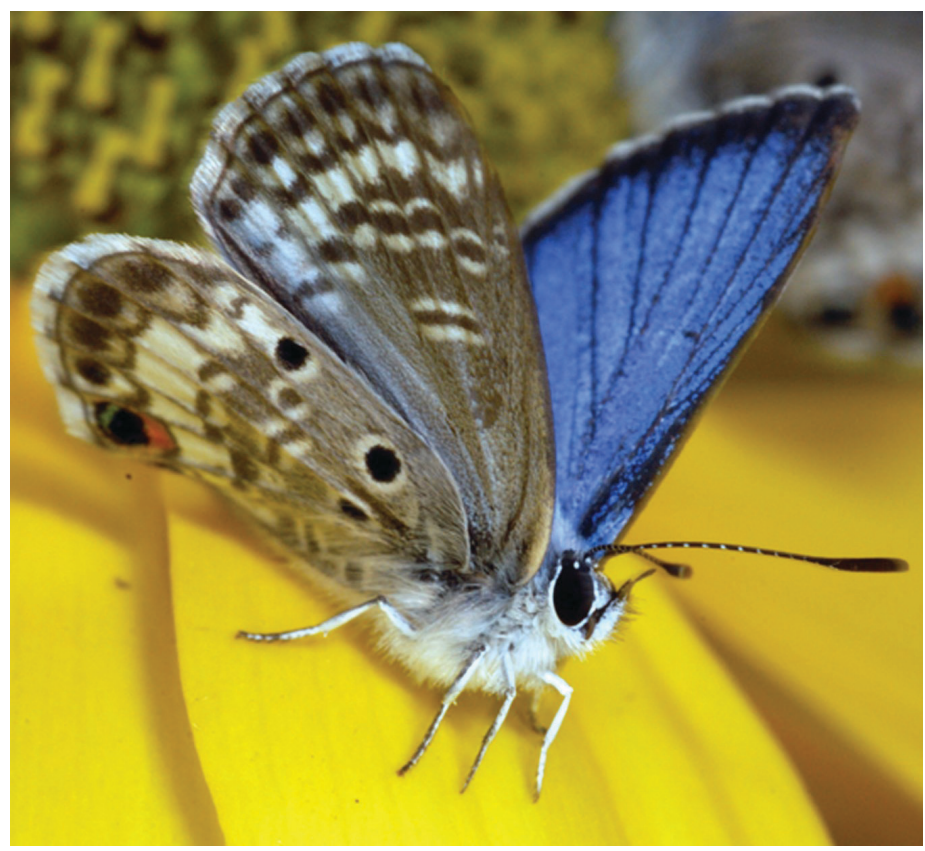

Figure 12. The Miami blue butterfly (Cyclargus thomasi bethunebakeri) is a federally endangered species. Impacts to this species' host plant caused by foraging green iguanas (Iguana iguana) may have contributed to the extirpation of this unique butterfly at Bahia Honda State Park in the Florida Keys.

Credits: Dr. Jaret Daniels, UF, Florida Museum of Natural History

\section{Impacts to People and Pets}

Green iguanas in Florida thrive in urban environments and are often seen basking openly in areas frequented by people. Although the iguanas are not usually aggressive towards people or pets, in some cases they can become serious hazards, as several news articles have reported. In one instance, a green iguana darted into the road, causing a bicyclist to crash. The man required stitches on his head, and the iguana did not survive the encounter (23). Green iguanas also may cause vehicle accidents when they dash across roads (14). In places in Florida with high densities of iguanas, they are often found as road-kills after being hit 
by cars (24). Green iguanas can become an aerial hazard during severe cold snaps in south Florida. Sustained temperatures of 30-40 degrees Fahrenheit cause green iguanas to become lethargic and stiff, and they may fall out of trees as a result. In fact, the National Weather Service in Miami declared an unofficial "falling iguana" alert in January of 2020, warning citizens to watch out for falling lizards and avoid getting too close to them on the ground in case the iguanas warmed up and acted defensively (25).

Green iguanas are also a known hazard to airplanes on the tarmac and have delayed flight departures and arrivals at the Miami International Airport because they bask on runways (14). They have also disrupted air traffic in Puerto Rico (26), and in 2011 the cost of managing iguanas (removing iguanas and their nests) at the island's busiest airport was $\$ 98,000(14)$.

In addition to being physical hazards, green iguanas in captivity are also known carriers of E. coli and Salmonella bacteria. In a study of captive green iguanas in Mexico, nearly $40 \%$ were found to carry E. coli strains that were resistant to antibiotics (27). However, there is no scientific evidence that indicates wild green iguanas in Florida transmit pathogens to humans. However, they will defecate on docks, pool decks, and patios, which is unsightly and unsanitary (15). Green iguanas are also a nuisance for homeowners and at botanical gardens because the lizards eat ornamental plants, such as orchids, hibiscus, roses, nasturtium, and caladiums (15). To protect vulnerable plants from foraging iguanas, wire mesh or electric fencing may need to be installed, and trees can be protected by wrapping them with sheet metal to exclude climbing iguanas (15).

The burrowing habits of green iguanas may damage watercontainment infrastructures. Green iguanas are well known for digging burrows as hiding places, and females lay eggs in nest burrows. Iguanas may dig these burrows along the banks of canals and levees as well as at the bases of sea walls. When this occurs at locations with high densities of iguanas, there is concern that their burrows may increase erosion and compromise the integrity of the structures (17). For example, in January of 2020, the city of West Palm Beach spent almost $\$ 2$ million on repairs to an aging, earthen dam, and green iguana burrows were blamed for contributing to the need for repairs (28).

\section{You Can Help!}

While green iguanas have not been regulated historically in Florida as either a Conditional or Prohibited species, the Florida Fish and Wildlife Conservation Commission
(FWC) approved new regulations in early 2021 reclassifying them, and numerous other species of large, high-risk reptiles, as Prohibited. As Prohibited species, they will no longer be allowed to be obtained as personal pets or for commercial use (with some limited exceptions). Other rules regarding these species, including their caging, were also updated. These rules took effect on April 29 $9^{\text {th }}, 2021$, pet owners and other entities in possession of these species have 90 days to come into compliance and 180 days to improve outdoor enclosures to comply with the new caging rules. Pet owners in possession of green iguanas prior to the April $29^{\text {th }}$ rule change have a 90 -day grace period ending on July $28^{\text {th }}, 2021$ in which they can apply for a free permit to keep their pet iguanas for the remainder of the pet's life. However, the iguana must be marked for individual identification via a passive integrated transponder (PIT) tag prior to a permit being issued. These "microchips" are commonly used for pet dogs. Additionally, all commercial breeding of green iguanas in Florida will be phased out by June $30^{\text {th }}$, 2024. Visit this FWC website to learn more about the new regulations and be sure to share this information with others: https://myfwc.com/wildlifehabitats/nonnatives/ rule-development/

If you have a pet iguana, or another exotic pet that you are no longer able to care for or do not want to keep, you can surrender it for adoption through the FWC's Exotic Pet Amnesty Program: https://myfwc.com/wildlifehabitats/ nonnatives/amnesty-program/ This program allows owners of exotic, nonnative, pets (i.e., not livestock or domestic pets such as cats and dogs) to relinquish their pet at no cost or penalty. Surrendered pets are rehomed with experienced, pre-approved adopters. Please, DO NOT release unwanted exotic pet reptiles such as iguanas. This is unethical (the lizard may starve to death or harm native species) and is also against the law in Florida.

Considered an invasive species, green iguanas are not protected in Florida except by anti-cruelty laws and can be humanely killed on private property year-round with landowner permission. In fact, the FWC wants to make sure that the public knows they can remove nonnative species, including green iguanas, from private properties so long as they can do so legally, safely, and humanely. Members of the public also may harvest iguanas from 25 FWC-managed public lands without a license or permit under Executive Order 20-17. However, captured iguanas cannot legally be released at other locations in Florida or transported live without a permit. If you are not capable of safely removing iguanas from your property, please seek assistance from a private, professional nuisance wildlife 
trapper. Be aware that there is a fee for professional iguana removal services. The FWC and the University of Florida Extension Service DO NOT conduct green iguana removal on private properties.

And finally, if you observe a green iguana in Florida, especially outside of the shaded area shown on the map in Figure 10, take a digital image of it and report your observation at IveGot1.org or through the free IveGot1 Smartphone app.

\section{Additional Information}

The FWC has a webpage devoted to green iguanas where you can find more information about their ecology and impacts as well as regulations governing captive iguanas. https://myfwc.com/wildlifehabitats/profiles/reptiles/ green-iguana/

For a list of public lands in southern Florida where iguanas and other introduced reptiles can be legally harvested, check this link. https://myfwc.com/wildlifehabitats/ nonnatives/python/removing/

This site is a great source of information about rules for people in current possession of pet green iguanas, with a very informative FAQ section. https://myfwc.com/ wildlifehabitats/nonnatives/rule-development/pet-owners/

For more information about FWC's Exotic Pet Amnesty Program, click this link. https://myfwc.com/ wildlifehabitats/nonnatives/amnesty-program/

If you have nuisance iguanas in your yard and want them removed, you should consider hiring a professional trapper-know there will be a fee for such services. To locate a nuisance wildlife trapper near you, see this web page. https://public.myfwc.com/HGM/NWT/NWTSearch.aspx

\section{References}

1. Garman, S. 1887. "On West Indian reptiles: Iguanidae." Bulletin of the Essex Institute 19:25-50.

2. Krysko, K. L., L. A. Somma, D. C. Smith, C. R. Gillette, D. Cueva, J. A. Wasilewski, K. M. Enge, et al. 2016. "New Verified Nonindigenous Amphibians and Reptiles in Florida through 2015, with Summary of Over 152 Years of Introductions." IRCF Reptiles \& Amphibians 23:110-143.

3. Iannone, B. V, III, S. Carnevale, M. B. Main, J. E. Hill, J. B. McConnell, S. A. Johnson, S. F. Enloe, M. Andreu, E. C.
Bell, J. P. Cuda, and S. M. Baker. 2020. "Invasive Species Terminology: Standardizing for Stakeholder Education." Journal of Extension 58: https://joe.org/joe/2020june/ a3.php

4. Dorcas, M. E., J. D. Willson, R. N. Reed, R. W. Snow, M. R. Rochford, M. A. Miller, W. E. Meshaka, et al. 2012. Severe Mammal Declines Coincide with Proliferation of Invasive Burmese Pythons in Everglades National Park. Proceedings of the National Academy of Sciences 197:2418-2422.

5. McCleery, R. A., A. Sovie, R. N. Reed, M. W. Cunningham, M. E. Hunter and K. M. Hart. 2015. "Marsh Rabbit Mortalities Tie Pythons to the Precipitous Decline of Mammals in the Everglades." Proceedings of the Royal Society B 282: 20150120.http://dx.doi.org/10.1098/ rspb.2015.0120

6. Miller, M. A., J. M. Kinsella, R. W. Snow, M. M. Hayes, B. G. Falk, R. N. Reed, F. J. Mazzotti, C. Guyer and C.M. Romagosa. 2017. "Parasite Spillover: Indirect Effects of Invasive Burmese Pythons." Ecology and Evolution 8:830-840.

7. Farrell T. M., J. Agugliaro, H. D. S. Walden, J. F. X. Wellehan, A. L. Childress, and C. M. Lind. 2019. "Spillover of Pentastome Parasites from Invasive Burmese Pythons (Python bivittatus) to Pygmy Rattlesnakes (Sistrurus miliarius), Extending Parasite Range in Florida, USA." Herpetological Review 50:73-76.

8. Krysko, K. L., K. M. Enge, and P. E. Moler. 2019. Amphibians and Reptiles of Florida. University of Florida Press, Gainesville. 706 pp.

9. Meshaka, W. E., Jr., H. T. Smith, E. Golden, J. A. Moore, S. Fitchett, E. M. Cowan, R. M. Engeman, S. R. Sekscienski and H. L. Cress. 2007. "Green Iguanas (Iguana iguana): The Unintended Consequence of Sound Wildlife Management Practices in a South Florida Park." Herpetological Conservation and Biology 2:149-156.

10. Townsend, J. H., K. L Krysko, and K. M. Enge. 2003. "Introduced Iguanas in Southern Florida: A History of More Than 35 Years." Iguana 10:111-118.

11. Meshaka, W. E., Jr., B. P. Butterfield, and J. B. Hague. 2004. The Exotic Amphibians and Reptiles of Florida. Kreiger Publishing Company, Malabar, FL. 155 pp. 
12. Bock, B. C. 2004. Iguana iguana. An online reference. Available at www.iucn-isg.org/species/iguana-species/ iguana-iguana/

13. King, W., and T. Krakauer. 1966. "The Exotic Herpetofauna of Southeast Florida." Quarterly Journal of the Florida Academy of Sciences. 29:144-154.

14. Falcón, W., J. D. Ackerman, W. Recart, and C. C. Daehler. 2013. "Biology and Impacts of Pacific Island Invasive Species." 10. Iguana iguana, the Green Iguana (Squamata: Iguanidae)." Pacific Science 2:157-186.

15. Krysko, K. L., K. M. Enge, E. M. Donlan, J. C. Seitz, and E. A. Golden. 2007. "Distribution, Natural History, and Impacts of the Introduced Green Iguana (Iguana iguana) in Florida." Iguana 1:2-17.

16. Kern, W. H., Jr. 2004. "Dealing with Iguanas in the South Florida Landscape." EDIS 2004 (15). https://doi. org/10.32473/edis-in528-2004.

17. Sementelli, A., H. T. Smith, W. E. Meshaka, Jr., and R. M. Engeman. 2008. "Just Green Iguanas? The Associated Costs and Policy Implications of Exotic Wildlife in South Florida." Public Works Management \& Policy 12:599-606.

18. Smith, H. T., W. E. Meshaka, Jr., G. H. Busch, and E. M. Cowan. 2007. "Gray Fox Predation of Nests as a Potential Limiting Factor in the Colonization Success of the Green Iguana in Southern Florida." Journal of Kansas Herpetology 23:7-8.

19. Meshaka, W. E., Jr. 2011. "A Runaway Train in the Making: The Exotic Amphibians, Reptiles, Turtles, and Crocodilians of Florida." Herpetological Conservation \& Biology 6 (Monograph1):1-101.

20. Campbell, A., and E. Maple. 2012. "Home Range Size and Potential for Exotic Seed Dispersal by Green Iguanas (Iguana iguana) in Southern Florida." Florida Scientist 75:96-99.

21. Florida Fish and Wildlife Conservation Commission. 2010. Miami Blue Butterfly Management Plan

22. U.S. Department of the Interior. 2012. Federal Register 77(67):20948-20986.
23. Croft, J. 2020. "Florida Bicyclist Injured in Collision with an Iguana." CNN. https://www.cnn.com/2020/07/18/us/ iguana-florida-bicycle-trnd/index.html

24. Smith, H. T., W. E. Meshaka, Jr., E. Golden, and E. M. Cowan. 2007. "The Appearance of the Exotic Green Iguana as Road-Kills in a Restored Urban Florida State Park: The Importance of an 11-Year Dataset." Journal of Kansas Herpetology 22:14-16.

25. Rice, D. 2020. “'Falling iguana' alert issued in Florida due to cold temperatures: 'Don't assume that they're dead." USA TODAY. https://www. usatoday.com/story/news/nation/2020/01/21/ falling-iguana-alert-florida-cold-weather/4533510002/

26. Engeman, R. M., H. T. Smith, and B. Constantin. "Invasive Iguanas as Airstrike Hazards at Luis Muñoz Marín International Airport, San Juan, Puerto Rico." 2005. Journal of Aviation/Aerospace Education \& Research 14:45-50.

27. Bautista-Trujillo, G. U., F. A. Gutiérrez-Miceli, L. Mandujano-García, M. A. Oliva-Llaven, C. IbarraMartínez, P. Mendoza-Nazar, B. Ruiz-Sesma, et al. 2020. "Captive Green Iguana Carries Diarrheagenic Escherichia coli Pathotypes." Frontiers in Veterinary Science 7 (99): 1-9.

28. Miller, K. 2020. "Invasive Iguanas: Burrowing Reptiles Blamed for \$1.8M of Damages to Palm Beach Dam." Palm Beach Post. https://www.tcpalm.com/story/news/ local/florida/2020/01/21/iguanas-not-just-nuisancethese-lizards-contributed-1-8-m-repair-bill-westpalm/4530432002/ 